\title{
The value of prophylactic vaccinations and antibiotic treatment in post-splenectomy patients: a review
}

This article was published in the following Dove Press journal:

Transplant Research and Risk Management

27 June 2012

Number of times this article has been viewed

\author{
AJ Jolanda Lammers \\ Department of Infectious diseases, \\ Tropical Medicine and AIDS, Academic \\ Medical Center, Amsterdam, The \\ Netherlands
}

\begin{abstract}
Although spleen preservation surgery and non-operative management are firstline treatment options, total splenectomy is frequently performed. Splenectomy is performed for a number of indications including idiopathic thrombocytopenic purpura, high-energetic trauma, and hematological malignancy. Following splenectomy, patients are at risk for overwhelming post-splenectomy infection (OPSI), a syndrome that presents with mild symptoms at onset but irreversible multi-organ-failure occurs within hours to days. Since the spleen plays an important role in the immune response to polysaccharide antigens, encapsulated bacteria such as pneumococci are the most frequently described causative organisms of OPSI. Although the incidence of OPSI is low, the associated mortality is reported to be as high as $80 \%$. Because of the overwhelming and frequently irreversible nature of this syndrome, prophylactic measures to prevent OPSI have been recommended. These recommendations include vaccination, use of antibiotics, and continuous patient education. After splenectomy, patients should receive immunizations against the encapsulated bacteria S. pneumoniae, $H$. influenza, and $N$. meningitidis. Antibiotic therapy should include prophylaxis as well as "on-demand" antibiotics when infection is suspected. Importantly, patients should receive ongoing education regarding the risks associated with asplenia and precautions to take when infection occurs and when traveling.
\end{abstract}

Keywords: S. pneumoniae, sepsis, splenectomy, vaccination

\section{The spleen}

The spleen has two major functions: (1) filtering and storing of blood cells, and (2) promoting a coordinated immune response to systemic pathogens. Based on its location in circulation combined with its unusual structure of a lymphoid-like compartment, the spleen has a unique architecture designed for these tasks while ensuring optimal immunological surveillance of the bloodstream.

The spleen consists of red pulp, white pulp, and the marginal zone, and is surrounded by a fibrous capsule of connective tissue. ${ }^{1}$ Red pulp is a complex network of arterioles; arterial blood arrives in cords that form an open blood system without endothelial lining. Blood then passes into the venous sinuses, which ultimately collects into the efferent vena lienalis. Sinuses contain stress-fibers, which are capable of forming slits when contracted. Aging erythrocytes, which have stiffened membranes, have difficulty passing through these slits and become trapped and phagocytosed by red pulp macrophages. ${ }^{2}$ Old or damaged erythrocytes, as well as foreign particulate matter, are thus filtered from circulating blood. Furthermore, contracted stress-fibers have been suggested to aid in sustaining a reservoir of red cells. Erythrophagocytosis
Correspondence: AJJ Lammers

Department of ITA, F4-2I7,

Academic Medical Center, Meibergdreef

9, II 05 AZ, Amsterdam,

The Netherlands

Tel +3 I 205669 I I I

Fax +3I 206972286

Email a.j.lammers@amc.uva.nl 
is also important in the recycling of iron, and the red pulp contributes to facilitating iron metabolism. ${ }^{1}$

White pulp, which performs immunological functions in the spleen, contains B and $\mathrm{T}$ cells. Its architecture is very similar to that of lymph nodes. In the $\mathrm{T}$ cell zone, $\mathrm{T}$ cells interact with dendritic cells and passing $\mathrm{B}$ cells, whereas in B cell-follicles, clonal expansion of activated B cells can take place, leading to isotype switching and somatic hypermutation. T and B cells from circulation are directed to their specific zones by chemokines. ${ }^{3,4}$

Between the red and the white pulp lies the marginal zone; lymphocytes continuously migrate from blood into white pulp and back, making the marginal zone a transit area where efficient identification of antigens and pathogens can take place. Specific populations of cells reside in the marginal zone (MZ), including MZ macrophages and MZ B cells. MZ macrophages have the unique capacity to directly capture whole encapsulated bacteria from circulation by binding specific polysaccharide antigens. ${ }^{5,6} \mathrm{MZ}$ macrophages and MZ B cells can subsequently directly interact with each other. ${ }^{7,8} \mathrm{MZ} \mathrm{B}$ cells can be activated by pathogen-degradation products, but are also specialized to detect blood-borne pathogens. They either respond swiftly by differentiating into IgM-producing plasma cells or gain the capacity to function as APCs and present antigens to the adaptive immune system in the nearby white pulp. ${ }^{9} 10$ Additionally, blood-borne dendritic cells that are temporarily present in the MZ are induced to migrate into white pulp upon activation and are thus responsible for initiating the adaptive immune response. ${ }^{1}$ After T cell activation by APCs in white pulp, B cells switch their isotype within B cell follicles and migrate back to the red pulp or remain in splenic germinal centers. ${ }^{11}$

\section{Immunological defects after splenectomy}

The crucial role of the spleen in protecting against pathogens became clear when King and Schumacker described a series of case reports in 1952 showing that after splenectomy, children experienced life-threatening infections. ${ }^{12}$ Their report demonstrated an association between splenectomy and fulminant, lethal sepsis established knowledge regarding increased susceptibility, particularly for encapsulated bacteria. ${ }^{13-15}$

Immunological defects after splenectomy are due to decreased clearance of particulate antigens from the circulation, diminished clearance of opsonized bacterial antigens, diminished primary humoral response to neoantigens, and diminished antibody response to polysaccharides. ${ }^{1}$ The principal problem encountered after splenectomy, however, is associated with impaired clearance of poorly opsonized antigens, such as encapsulated bacteria. The polysaccharide capsule impedes opsonization through immunoglobulins or complement upon entering the circulation. The spleen is much more efficient in removing these poorly opsonized pathogens than any other organ, including the liver. Furthermore, IgM memory B cells, which are responsible for protecting against infection from encapsulated bacteria, require the spleen for their survival. IgM memory B cells are undetectable in splenectomized patients. ${ }^{16}$ Collectively, all of these immunological defects contribute to decreased clearance of encapsulated organisms, which can result in severe and overwhelming intravascular infection.

\section{Diminished splenic function}

Splenectomy is the most obvious cause of asplenia. In contrast, congenital asplenia is a rare and often unrecognized condition. In addition to the asplenic state, a large group of patients have hyposplenia, in which the spleen remains in the body but is dysfunctional. The underlying causes of hyposplenia are heterogeneous and are not well-understood. The best described cohort with hyposplenia or functional asplenia is patients with sickle cell disease. It is well-known that patients with sickle cell disease are susceptible to pneumococcal infection, particularly children under the age of three years. Splenic function decreases rapidly during this disease because vaso-occlusive sickling in the splenic sinuses results in splenic auto-infarction and atrophy. The incidence of pneumococcal disease in children decreased dramatically (by approximately 90\%) after introduction of pneumococcal vaccination into the routine childhood immunization schedule. ${ }^{17}$ Previously, it was shown that when these children received penicillin prophylaxis, the pneumococcal infection rate decreased by $84 \%{ }^{18}$ Other diseases known to be associated with diminished splenic function include inflammatory bowel disease (Crohn's disease and ulcerative colitis) $)^{19,20}$ and Celiac disease. ${ }^{20-23}$

Unfortunately, to date, there is no common diagnostic method for evaluating splenic function. Large studies comparing methods available for testing splenic function, as well as the sensitivity and specificity of these methods in various patient populations have not been conducted. Recently, literature regarding how to measure splenic function was reviewed and it was concluded that ${ }^{99} \mathrm{~m}$ Tc-labelled heataltered autologous erythrocyte scintigraphy combined with multimodality SPECT-CT appears to be the best approach since all facets of splenic function are evaluated using these methods. ${ }^{24}$ Unfortunately, the population of hyposplenic patients is too large to screen using scintigraphy. Therefore, a 
cheaper, simpler, more accessible method is necessary. In the literature, determining the percentage of pitted erythrocytes (erythrocytes with membrane irregularities) in patients with potential hyposplenia may serve this purpose $;^{25,26}$ however, evaluating other or potentially new (immunological) markers remains necessary. Importantly, the absence of Howell Jolly bodies, a commonly used marker for determining splenic function, is not indicative of normal spleen function. ${ }^{27,28}$ The presence of Howell Jolly bodies, however, should prompt further diagnostic evaluation of splenic function.

Therefore, most patients with hyposplenia, as well as their physicians, are not well-informed regarding splenic function and the potentially increased susceptibility for infection. Immunological defects after spleen-preserving surgery such as splenic embolization are unknown. ${ }^{29}$

\section{Preventing infection Post-splenectomy sepsis}

As described above, when the spleen is removed, patients are at an overwhelming risk of developing intravascular infection. This syndrome is referred to as overwhelming post-splenectomy infection (OPSI) or post-splenectomy sepsis and is characterized by a mild onset with flu-like symptoms such as low grade fever, chills, muscle aches, and nausea. However, subsequent rapid deterioration may occur over the course of hours rather than days, leading to fulminant sepsis, disseminated intravascular coagulation, and multi-organ failure. ${ }^{30}$ The incidence of OPSI is estimated to be only $2-5$ per 1000 asplenic patients per year, ${ }^{31}$ whereas the lifetime risk for developing OPSI is estimated to be $5 \% .{ }^{32}$ Although more than half of these infections occur within the first two years after splenectomy, this increased risk is life-long. ${ }^{33,34}$ Although the incidence is low, mortality associated with OPSI is high. Reported values in the literature vary between $50 \%$ and $70 \% .{ }^{34,35}$ Importantly, $68 \%$ of patients die within the first 24 hours, and $80 \%$ within 48 hours after disease onset. ${ }^{35}$

The risk for developing OPSI varies among different patient groups. Age is an important factor, and the young and elderly are at the highest risk. Furthermore, the primary indication for splenectomy influences OPSI incidence; patients undergoing splenectomy for trauma have a relatively low risk of OPSI, whereas patients undergoing splenectomy for spherocytosis, idiopathic thrombocytopenic purpura, or portal hypertension are at an intermediate risk. The highest risk of OPSI is associated with splenectomy for thalassemia and Hodgkin lymphoma. ${ }^{36}$ The large and inhomogeneous group of patients with (potential) functional asplenia, including patients with sickle cell disease, celiac disease, or inflammatory bowel disease, should be considered to be at risk for OPSI.

Encapsulated bacteria are the primary causative organisms of OPSI. Streptococcus pneumoniae causes $70 \%$ of bacteraemic episodes following splenectomy. ${ }^{35}$ Other pathogens associated with OPSI include Haemophilus influenzae, Neisseria meningitidis (meningococcus), Escherichia coli, and Pseudomonas spp.

Preventing overwhelming sepsis in patients with asplenia is relatively uncomplicated. Patients can be vaccinated against these microorganisms to prevent pneumococcal, meningococcal, or H. influenzae disease. Furthermore, antibiotics are available for treating overwhelming sepsis. Since OPSI can rapidly progress into fulminant disease, patients should begin therapy at the first symptoms of infection by taking antibiotics that are kept at home and seek medical help immediately. There have been recommendations published in international literature, ${ }^{37,38}$ but most studies also show that these recommendations are not being followed. ${ }^{39-42}$ The most important barrier preventing physicians from adhering to best-practice procedures is the lack of uniform guidelines for patients without a spleen. Other reported barriers include unclear responsibilities between inpatient and outpatient caregivers and lack of communication between hospital specialists and general practitioners. ${ }^{43}$

\section{Recommendations for patients after splenectomy}

General recommendations for preventing invasive disease after splenectomy are trifold and include the following: (1) immunizations, (2) antibiotic prophylaxis and therapy, and (3) patient education..$^{3744}$ Moreover, patients should be vaccinated against the encapsulated bacteria $S$. pneumoniae, $H$. influenzae $\mathrm{B}$, and $N$. meningitidis $\mathrm{C}$, as well as receive annual influenza vaccination.

Pneumococcal vaccination consists of a combined schedule of a conjugated vaccine (with the highest available number of pneumococcal serotypes) and polysaccharide vaccination. Immunization against $H$. influenzae $\mathrm{B}$ and $N$. meningitidis $\mathrm{C}$ is recommended for all asplenic patients if not previously administered. The type of meningococcal vaccine that should be administered in asplenic or hyposplenic adults depends on the epidemiology of the disease-causing strains of $N$. meningitidis in each country. In Western Europe, it is generally advised to immunize against serotype $\mathrm{C}$; however, when travelling further abroad, the quadrivalent conjugate vaccine (against serotypes A, C, Y, and W135) is recommended to be used as a complement. 
Lastly, all asplenic patients should receive annual influenza immunization to prevent secondary bacterial infection. Timing of immunizations should ideally occur prior to splenectomy, preferably at least two weeks, since the immune response to vaccination is partially dependent on the spleen. ${ }^{37,44}$ In cases of urgent or inadvertent splenectomy, it is recommended to wait for an interval of at least 2 weeks after the surgery before immunization since titer responses have been shown to increase by that time..$^{45}$

Furthermore, patients should use continuous prophylactic antibiotic therapy during the first 2 years after splenectomy since more than half of all septic episodes occur within this time period. Moreover, patients always should have "ondemand" antibiotics in their possession to use in case of (suspected) infection. Since OPSI can be irreversible within hours, patients should take these antibiotics immediately and subsequently seek medical advice.

Considering local resistance patterns per country, in Europe, it is generally advised to use penicillin. Notably, some controversy exists, particularly regarding the benefit of antibiotic prophylactic use in adults as opposed to children, development of bacterial resistance, and treating viral infections using antibiotics. Moreover, data examining new pneumococcal vaccination schedules (ie, polysaccharide vaccine combined with a conjugated vaccine), are not yet available but are expected to be more effective. In time, these combined immunizations may yield more limited usefulness of continuous prophylaxis. In absence of these data, however, treatment using antibiotics is still considered to be a valuable recommendation.

Potentially even more importantly than the chemoprophylaxis described above, patients should be educated regarding the infectious risks associated with asplenia. Informing patients is an important and effective strategy in preventing $\mathrm{OPSI}^{46}$ and should not be a one-time event but information should be given repeatedly. Specific recommendations for patients include being sure to acquire immunizations, to use antibiotics instantly, and seek medical help in case of fever or chills, undergo physical examination by a physician in case of illness, and seek expert advice when traveling to areas where pathogens causing severe diseases (ie, malaria, babesiosis) are endemic. ${ }^{37,47-49}$ Furthermore, splenic patients are recommended to carry a Medical Alert symbol to ensure that adequate therapy is provided.

\section{Efficacy of vaccines in asplenic patients}

The efficacy of vaccination during asplenia shows variable results. Some studies have shown a limited rise of antibody titers following immunization when the spleen has been removed, whereas others show adequate induction of protective antibody levels following splenectomy. ${ }^{50-54}$ Therefore, immunization should take place before splenectomy. If this is not possible, vaccination should not take place for at least two weeks after the surgery. Polysaccharide pneumococcal immunization during asplenia may not be as potent as conjugated vaccines since the response to capsular polysaccharides is completely dependent on the spleen. Additionally, not all potentially causative pneumococcal serotypes are covered within the vaccines. Therefore, a combined strategy of immunizations and adequate use of antibiotics, reinforced by well-informed patients, is probably the most effective method for preventing OPSI.

\section{Conclusion}

Patients who undergo splenectomy or those with hyposplenic function are at risk for overwhelming post-splenectomy infection, which has a high mortality rate. Preventive measures include vaccination against encapsulated bacteria, use of antibiotic prophylaxis and therapy, and ongoing patient education. Unfortunately, in absence of uniform guidelines, preventive measures are repeatedly reported to be inadequately practiced. The availability of a guideline to ensure that caregivers and patients are well-informed regarding the need for immunizations, combined with adequate use of antibiotic therapy and prophylaxis, as well as measurements to take upon travelling, is likely the most effective method for improving the quality of care for asplenic patients and reducing the number of fatal infections.

\section{Disclosure}

The author reports no conflicts of interest in this work.

\section{References}

1. Mebius RE, Kraal G. Structure and function of the spleen. Nat Rev Immunol. 2005;5(8):606-616.

2. Bratosin D, Mazurier J, Tissier JP, et al. Cellular and molecular mechanisms of senescent erythrocyte phagocytosis by macrophages. A review. Biochimie. 1998;80(2):173-195.

3. Ansel KM, Ngo VN, Hyman PL, et al. A chemokine-driven positive feedback loop organizes lymphoid follicles. Nature. 2000;406(6793): 309-314.

4. Forster R, Schubel A, Breitfeld D, et al. CCR7 coordinates the primary immune response by establishing functional microenvironments in secondary lymphoid organs. Cell. 1999;99(1):23-33.

5. Geijtenbeek TB, Groot PC, Nolte MA, et al. Marginal zone macrophages express a murine homologue of DC-SIGN that captures blood-borne antigens in vivo. Blood. 2002;100(8):2908-2916.

6. Koppel EA, Wieland CW, van den Berg V, et al. Specific ICAM-3 grabbing nonintegrin-related 1 (SIGNR1) expressed by marginal zone macrophages is essential for defense against pulmonary Streptococcus pneumoniae infection. Eur J Immunol. 2005;35(10):2962-2969. 
7. Koppel EA, Litjens M, van den Berg V, van Kooijk Y, Geijtenbeek TB. Interaction of SIGNR1 expressed by marginal zone macrophages with marginal zone B cells is essential to early IgM responses against Streptococcus pneumoniae. Mol Immunol. 2008;45(10):2881-2887.

8. You Y, Myers RC, Freeberg L, et al. Marginal zone B cells regulate antigen capture by marginal zone macrophages. $J$ Immunol. 2011; 186(4):2172-2181.

9. van Rooijen N. Direct intrafollicular differentiation of memory B cells into plasma cells. Immunol Today. 1990;11(5):154-157.

10. Lopes-Carvalho T, Kearney JF. Development and selection of marginal zone B cells. Immunol Rev. 2004;197:192-205.

11. Pape KA, Kouskoff V, Nemazee D et al. Visualization of the genesis and fate of isotype-switched B cells during a primary immune response. J Exp Med. 2003;197(12):1677-1687.

12. King H, Shumacker HB Jr. Splenic studies. I. Susceptibility to infection after splenectomy performed in infancy. Ann Surg. 1952;136(2): 239-242.

13. Bohnsack JF, Brown EJ. The role of the spleen in resistance to infection. Annu Rev Med. 1986;37:49-59.

14. Horan M, Colebatch JH. Relation between splenectomy and subsequent infection. A clinical study. Arch Dis Child. 1962;37:398-414.

15. Brigden ML. Overwhelming postsplenectomy infection still a problem. West J Med. 1992;157(4):440-443.

16. Kruetzmann S, Rosado MM, Weber H, et al. Human immunoglobulin M memory B cells controlling Streptococcus pneumoniae infections are generated in the spleen. $J$ Exp Med. 2003;197(7):939-945.

17. Halasa NB, Shankar SM, Talbot TR, et al. Incidence of invasive pneumococcal disease among individuals with sickle cell disease before and after the introduction of the pneumococcal conjugate vaccine. Clin Infect Dis. 2007;44(11):1428-1433.

18. Gaston MH, Verter JI, Woods G, et al. Prophylaxis with oral penicillin in children with sickle cell anemia. A randomized trial. $N$ Engl $\mathrm{J} \mathrm{Med}$. 1986;314(25):1593-1599.

19. Di Sabatino A, Rosado MM, Ciccocioppo R, et al. Depletion of immunoglobulin M memory B cells is associated with splenic hypofunction in inflammatory bowel disease. Am J Gastroenterol. 2005;100(8): 1788-1795.

20. Muller AF, Toghill PJ. Hyposplenism in gastrointestinal disease. Gut. 1995;36(2):165-167.

21. Corazza GR, Zoli G, Di Sabatino A, Ciccocioppo R, Gasbarrini G. A reassessment of splenic hypofunction in celiac disease. $\mathrm{Am}$ J Gastroenterol. 1999;94(2):391-397.

22. Di Sabatino A, Rosado MM, Cazzola P, et al. Splenic hypofunction and the spectrum of autoimmune and malignant complications in celiac disease. Clin Gastroenterol Hepatol. 2006;4(2):179-186.

23. Thomas HJ, Wotton CJ, Yeates D, Ahmad T, Jewell DP, Goldacre MJ. Pneumococcal infection in patients with coeliac disease. Eur J Gastroenterol Hepatol. 2008;20(7):624-628.

24. de Porto AP, Lammers AJ, Bennink RJ, ten Berge IJ, Speelman P, Hoekstra JB. Assessment of splenic function. Eur J Clin Microbiol Infect Dis. 2010;29(12):1465-1473.

25. Corazza GR, Bullen AW, Hall R, Robinson PJ, Losowsky MS. Simple method of assessing splenic function in coeliac disease. Clin Sci (Lond) 1981;60(1):109-113

26. Corazza GR, Tarozzi C, Vaira D, Frisoni M, Gasbarrini G. Return of splenic function after splenectomy: how much tissue is needed? $\mathrm{Br}$ Med $J$ (Clin Res Ed). 1984;289(6449):861-864.

27. Gotthardt M, Broker S, Schlieck A, et al. Scintigraphy with $99 \mathrm{mTc}-$ labeled heat-altered erythrocytes in diagnosing hyposplenia: prospective comparison to $99 \mathrm{mTc}$-labeled colloids and colour-coded duplex ultrasonography. Nuklearmedizin. 2007;46(4):135-140.

28. Lammers AJ, de Porto AP, Bennink RJ, et al. Hyposplenism: Comparison of different methods for determining splenic function. $A m$ J Hematol. 2012;87(5):484-489.

29. Skattum J, Naess PA, Gaarder C. Non-operative management and immune function after splenic injury. Br J Surg. 2012;99 Suppl 1: $59-65$.
30. Okabayashi T, Hanazaki K. Overwhelming postsplenectomy infection syndrome in adults - a clinically preventable disease. World $J$ Gastroenterol. 2008;14(2):176-179.

31. Brigden ML, Pattullo A, Brown G. Pneumococcal vaccine administration associated with splenectomy: the need for improved education, documentation, and the use of a practical checklist. $\mathrm{Am} \mathrm{J}$ Hematol. 2000;65(1):25-29.

32. Lynch AM, Kapila R. Overwhelming postsplenectomy infection. Infect Dis Clin North Am. 1996;10(4):693-707.

33. Cullingford GL, Watkins DN, Watts AD, Mallon DF. Severe late postsplenectomy infection. Br J Surg. 1991;78(6):716-721.

34. Styrt B. Infection associated with asplenia: risks, mechanisms, and prevention. Am J Med. 1990;88(5N):33N-42N.

35. Holdsworth RJ, Irving AD, Cuschieri A. Postsplenectomy sepsis and its mortality rate: actual versus perceived risks. $\mathrm{Br} J$ Surg. 1991;78(9):1031-1038.

36. Lutwick LI. Infections in asplenic patients. In: Mandell GL, Bennett JE, Dolin R, eds. Principles and Practice of Infectious Diseases. 5th ed. Philadelphia: Churcill Livingstone; 2000:3169-3176.

37. Davies JM, Barnes R, Milligan D, for British Committee for Standards in Haematology, Working Pary of the Haematology/Ontology Task Force. Update of guidelines for the prevention and treatment of infection in patients with an absent or dysfunctional spleen. Clin Med. 2002;2(5):440-443.

38. Mourtzoukou EG, Pappas G, Peppas G, Falagas ME. Vaccination of asplenic or hyposplenic adults. Br J Surg. 2008;95(3):273-280.

39. Bruni L, Bayas JM, Vilella A, Conesa A. Vaccination coverage in adults undergoing splenectomy: evaluation of hospital vaccination policies. Epidemiol Infect. 2006;134(4):837-844.

40. Kyaw MH, Holmes EM, Chalmers J, Jones IG, Campbell H. A survey of vaccine coverage and antibiotic prophylaxis in splenectomised patients in Scotland. J Clin Pathol. 2002;55(6):472-474.

41. Ramachandra J, Bond A, Ranaboldo C, Cullis J. An audit of postsplenectomy prophylaxis - are we following the guidelines? Ann $R$ Coll Surg Engl. 2003;85(4):252-255.

42. Waghorn DJ. Overwhelming infection in asplenic patients: current best practice preventive measures are not being followed. $J$ Clin Pathol. 2001;54(3):214-218.

43. Lammers AJJ, Hoekstra JB, Speelman P, Lombarts KM. Physicians report barriers to deliver best practice care for asplenic patients: a cross-sectional survey. PLoS One. 2011;6(3):e17302.

44. Working Party of the British Committee for Standards in Haematology Clinical Haematology Task Force, UK. Guidelines for the prevention and treatment of infection in patients with an absent or dysfunctional spleen. Working Party of the British Committee for Standards in Haematology Clinical Haematology Task Force. BMJ. 1996;312(7028):430-434.

45. Shatz DV. Vaccination considerations in the asplenic patient. Expert Rev Vaccines. 2005;4(1):27-34.

46. El-Alfy MS, El-Sayed MH. Overwhelming postsplenectomy infection: is quality of patient knowledge enough for prevention? Hematol $\mathrm{J}$. 2004;5(1):77-80.

47. Krause PJ, Gewurz BE, Hill D, et al. Persistent and relapsing babesiosis in immunocompromised patients. Clin Infect Dis. 2008;46(3):370-376.

48. Lipman HM. Preventing severe infection after splenectomy: risk of malaria and meningitis increases with asplenia. BMJ. 2005; 331(7516):576.

49. Pers C, Gahrn-Hansen B, Frederiksen W. Capnocytophaga canimorsus septicemia in Denmark, 1982-1995: review of 39 cases. Clin Infect Dis. 1996;23(1):71-75.

50. Ammann AJ, Addiego J, Wara DW, Lubin B, Smith WB, Mentzer WC. Polyvalent pneumococcal-polysaccharide immunization of patients with sickle-cell anemia and patients with splenectomy. $N$ Engl J Med. 1977;297(17):897-900.

51. Cherif H, Landgren O, Konradsen HB, Kalin M, Bjorkholm M. Poor antibody response to pneumococcal polysaccharide vaccination suggests increased susceptibility to pneumococcal infection in splenectomized patients with hematological diseases. Vaccine. 2006;24(1):75-81. 
52. Hosea SW, Burch CG, Brown EJ, Berg RA, Frank MM. Impaired immune response of splenectomised patients to polyvalent pneumococcal vaccine. Lancet. 1981;1(8224):804-807.

53. Giebink GS, Le CT, Cosio FG, Spika JS, Schiffman G. Serum antibody responses of high-risk children and adults to vaccination with capsular polysaccharides of Streptococcus pneumoniae. Rev Infect Dis. 1981; 3 Suppl: S168-S178.
54. Lee HJ, Kang JH, Henrichsen J, et al. Immunogenicity and safety of a 23 -valent pneumococcal polysaccharide vaccine in healthy children and in children at increased risk of pneumococcal infection. Vaccine. 1995;13(16):1533-1538.

\section{Publish your work in this journal}

Transplant Research and Risk Management is an international, peerreviewed open access journal focusing on all aspects of transplantation and risk management to achieve optimal outcomes in the recipient improving survival and quality of life. The journal welcomes submitted papers covering original research, basic science, clinical studies, reviews \& evaluations, guidelines, expert opinion and commentary, case reports and extended reports. The manuscript management system is completely online and includes a very quick and fair peer-review system, which is all easy to use. Visit http://www.dovepress.com/ testimonials.php to read real quotes from published authors. 